\section{Carcinoma de células escamosas del}

\section{escroto}

Medrano-Leos G, Álvarez-Mejía H, Magos-Aquino N, Alemán-Meza L, García-Gutiérrez S

Resumen

ANTECEDENTES: el carcinoma de células escamosas del escroto es poco frecuente, con escasos reportes en la bibliografía. Suele afectar a pacientes de avanzada edad, no genera síntomas y provoca una lesión ulcerada sangrante, de bordes indurados en el escroto.

CASO CLÍNICO: paciente de 83 años de edad, fogonero y mecánico, con exposición crónica al humo de leña y diversos agentes químicos. Ingresó al servicio de Urología del Centro Médico Nacional La Raza, con úlcera sangrante en el hemiescroto izquierdo, de 12 meses de evolución. A la exploración física se identificó una lesión superficial de $3 \times 2 \mathrm{~cm}$, ovoide, de bordes irregulares, ulcerada, con escaso sangrado; no se palparon ganglios linfáticos. La tomografía computada descartó datos de metástasis pulmonares, óseas o hepáticas. Tampoco evidenció enfermedad ganglionar locorregional ni a distancia. La estadificación se realizó según los criterios de Lowe para carcinoma de escroto y TNM de carcinoma de células escamosas. Se efectuó la disección de la lesión en su totalidad, mediante una incisión en el huso de bordes amplios de aproximadamente $2 \mathrm{~cm}$. El paciente tuvo evolución posquirúrgica adecuada; se descartó el tratamiento coadyuvante y hasta el momento permanece en vigilancia.

PALABRAS CLAVE: carcinoma de células escamosas, cáncer escrotal, exposición ocupacional.

Rev Mex Urol. 2017 may;77(3):219-224.

\section{Squamous cell carcinoma of the scrotum}

Medrano-Leos G, Álvarez-Mejía H, Magos-Aquino N, Alemán-Meza L, García-Gutiérrez S

\section{Abstract}

BACKGROUND: Squamous cell carcinoma of the scrotum is a rare entity with only a few reports in the medical literature. It usually presents in elderly patients, is asymptomatic, and causes a bleeding, ulcerated, hard-edged lesion on the scrotum.

CLINICAL CASE: An 83-year-old man that worked as a chimney sweep and a mechanic was chronically exposed to wood smoke and different chemical agents. He was admitted to the Urology Service with a bleeding ulcer on the left hemiscrotum of 12-month progression.
Servicio de Urología, Hospital General Dr. Gaudencio González Garza, Centro Médico Nacional La Raza, Universidad Nacional Autónoma de México, México, Ciudad de México.

Recibido: diciembre 2016

Aceptado: abril 2017

Correspondencia

Dr. Guillermo Medrano Leos

dr_guillermo_medrano@hotmail.com

Este artículo debe citarse como

Medrano-Leos G, Álvarez-Mejía H, Magos-Aquino N, Alemán-Meza L, García-Gutiérrez S. Carcinoma de células escamosas del escroto. Rev Mex Urol. 2017 mayo;77(3):219-224. 
Physical examination identified a $3 \times 2 \mathrm{~cm}$ superficial ovoid lesion with scant bleeding. No lymph nodes were palpated. Computed tomography showed no evidence of lung, bone, or liver metastases or signs of locoregional or distant lymph node disease. Scrotal carcinoma staging was carried out with the Lowe classification and the TNM classification. The lesion was completely dissected, employing a wide spindle-shaped incision with approximately $2 \mathrm{~cm}$ margins. The patient had adequate postoperative progression, did not receive adjuvant therapy, and is currently under surveillance.

KEY WORDS: Squamous cell carcinoma; Scrotal cancer; Occupational exposure
Servicio de Urología, Hospital General Dr. Gaudencio González Garza, Centro Médico Nacional La Raza, Universidad Nacional Autónoma de México, México, Ciudad de México.

Correspondence

Dr. Guillermo Medrano Leos dr_guillermo_medrano@hotmail.com

\section{ANTECEDENTES}

El carcinoma de células escamosas del escroto es una neoplasia poco frecuente (sólo se han reportado casos aislados). ${ }^{1-3}$ En Estados Unidos se ha reportado una incidencia de 10 casos al año, ${ }^{4}$ cuya tasa aumentó de 0.49 a 0.95 en 100,000 habitantes de 1973 a $2002 .^{5}$

La variante de células escamosas es la más común dentro de las neoplasias del escroto. ${ }^{5}$ La supervivencia estimada después de la cirugía es de 115 meses (límites de 97-133). Este tumor es mucho más sombrío-agresivo comparado con otras estirpes. ${ }^{6,7}$

Su origen se asocia con diversas teorías, pero una de las más importantes es la labor de los deshollinadores (limpiadores de chimeneas) descrita por Percivall Pott en 1775. También se ha relacionado con irritación crónica, ya sea por el uso de orinales de plástico, ${ }^{8}$ mostaza de nitrógeno tópica, ${ }^{9}$ incluso alquitrán de hulla. ${ }^{10}$ Esta neoplasia se considera un indicador centinela de salud, debido a su asociación con mala higiene. ${ }^{11}$

Suele afectar a pacientes alrededor de la séptima década de edad, provoca síntomas inespecíficos y genera una lesión evidente en la región escro- tal. El 18\% de los pacientes con neoplasias de origen escrotal desarrollan uno o más tumores después de establecer el diagnóstico, ya sea pulmonar, cutáneo y un segundo escrotal, entre los más comunes. ${ }^{5}$

Presentamos el caso de un paciente "fogonero y mecánico" a quien se diagnóstico con carcinoma de células escamosas del escroto.

\section{CASO CLÍNICO}

Paciente masculino de 83 años de edad, con antecedente ocupacional de fogonero y mecánico, con exposición crónica al humo de leña y químicos como: arsénico, ácido clorhídrico, ácido sulfúrico, solventes, fertilizantes y pesticidas. Ingresó al servicio de Urología del Centro Médico Nacional La Raza para protocolo de estudio, quien refirió una úlcera sangrante en el hemiescroto izquierdo de 12 meses de evolución, previamente tratado con antibióticos, sin reacción satisfactoria.

A la exploración física se identificó una lesión superficial de $3 \times 2 \mathrm{~cm}$, ovoide, de bordes irregulares, ulcerada, con escaso sangrado, localizada en la parte inferior del hemiescroto izquierdo; no se palparon ganglios linfáticos (Figura 1). 


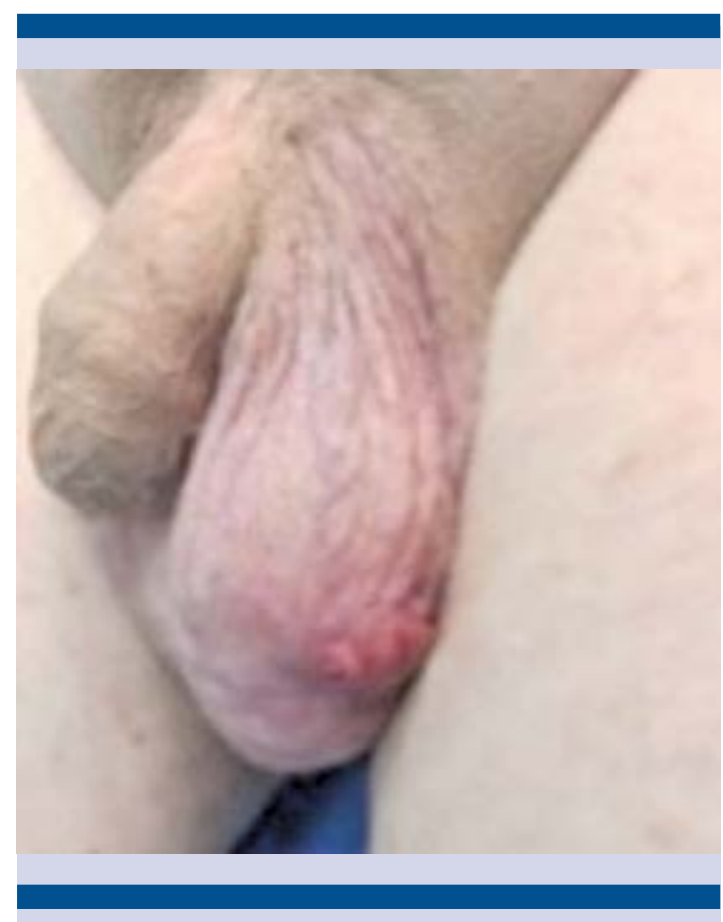

Figura 1. Hemiescroto izquierdo con lesión ulcerada sangrante.

La tomografía computada descartó datos de metástasis pulmonares, óseas o hepáticas. Tampoco evidenció enfermedad ganglionar locorregional ni a distancia.

La estadificación se realizó según los criterios de Lowe para carcinoma de escroto (Cuadro 1) y TNM de carcinoma de células escamosas (Cuadro 2): enfermedad confinada al escroto, ideal para exéresis completa.

Se decidió programar para exéresis de la lesión versus hemiescrotectomía, con probable orquiectomía izquierda. La cirugía se efectuó en mayo de 2016, con disección de la lesión en su totalidad, mediante una incisión en el huso de bordes amplios de aproximadamente $2 \mathrm{~cm}$ (Figura 2).

En la exploración del testículo ipsilateral no se observaron datos macroscópicos de extensión
Cuadro 1. Clasificación de Lowe para carcinoma de células escamosas del escroto.

\begin{tabular}{|c|c|}
\hline$A_{1}$ & Enfermedad confinada al escroto. \\
\hline $\mathrm{A}_{2}$ & $\begin{array}{l}\text { Enfermedad localmente avanzada, que afecta } \\
\text { estructuras adyacentes (pene, perineo, testículo y } \\
\text { hueso pélvico), por continuidad, sin evidente } \\
\text { metástasis. }\end{array}$ \\
\hline B & $\begin{array}{c}\text { Metástasis de ganglios linfáticos superficiales } \\
\text { resecables. }\end{array}$ \\
\hline C & $\begin{array}{c}\text { Metástasis de ganglios linfáticos pélvicos u otras } \\
\text { metástasis irresecables. }\end{array}$ \\
\hline $\mathrm{D}$ & $\begin{array}{c}\text { Metástasis fuera de los ganglios linfáticos regio- } \\
\text { nales. }\end{array}$ \\
\hline
\end{tabular}

Cuadro 2. Clasificación TNM para estadificación de carcinoma de células escamosas.

\begin{tabular}{|c|c|c|c|}
\hline Etapa & $\begin{array}{l}\text { Tumor } \\
\text { primario }\end{array}$ & $\begin{array}{c}\text { Ganglios linfáticos } \\
\text { regionales }\end{array}$ & $\begin{array}{l}\text { Metástasis } \\
\text { a distancia }\end{array}$ \\
\hline 0 & Tis: in situ & $\begin{array}{c}\mathrm{N} 0=\text { ganglios } \\
\text { ausentes }\end{array}$ & Mo \\
\hline 1 & $\begin{array}{c}\mathrm{T} 1: \text { tumor } \leq 2 \\
\mathrm{~cm}\end{array}$ & No & Mo \\
\hline \multirow{2}{*}{2} & $\begin{array}{l}\text { T2: tumor }>2 \\
\text { pero }<5 \mathrm{~cm}\end{array}$ & No & Mo \\
\hline & $\begin{array}{c}\mathrm{T} 3=\underset{\mathrm{tumor}}{\mathrm{cm}} \\
\end{array}$ & No & Mo \\
\hline \multirow[b]{2}{*}{3} & $\begin{array}{l}\text { T4: invasión de } \\
\text { las estructuras }\end{array}$ & No & Mo \\
\hline & $\begin{array}{c}\text { dérmicas más } \\
\text { profundas } \\
\text { Cualquier T }\end{array}$ & $\begin{array}{l}\text { N 1: ganglios lin- } \\
\text { fáticos regionales } \\
\text { coexistentes }\end{array}$ & Mo \\
\hline 4 & Cualquier $\mathrm{T}$ & Cualquier $\mathrm{T}$ & $\begin{array}{l}\text { M 1: } \\
\text { metástasis a } \\
\text { distancia }\end{array}$ \\
\hline
\end{tabular}

tumoral, por lo que se realizó el cierre primario de la herida (Figura 3).

La pieza quirúrgica se envió al servicio de Patología, que reportó los siguientes hallazgos:

- Macroscópicos: espécimen en forma de huso, de $6.5 \times 4.0 \times 2.0 \mathrm{~cm}$, con lesión hiperqueratósica de $2.7 \times 2.0 \mathrm{~cm}$, blanquecina, de aspecto empedrado, con 


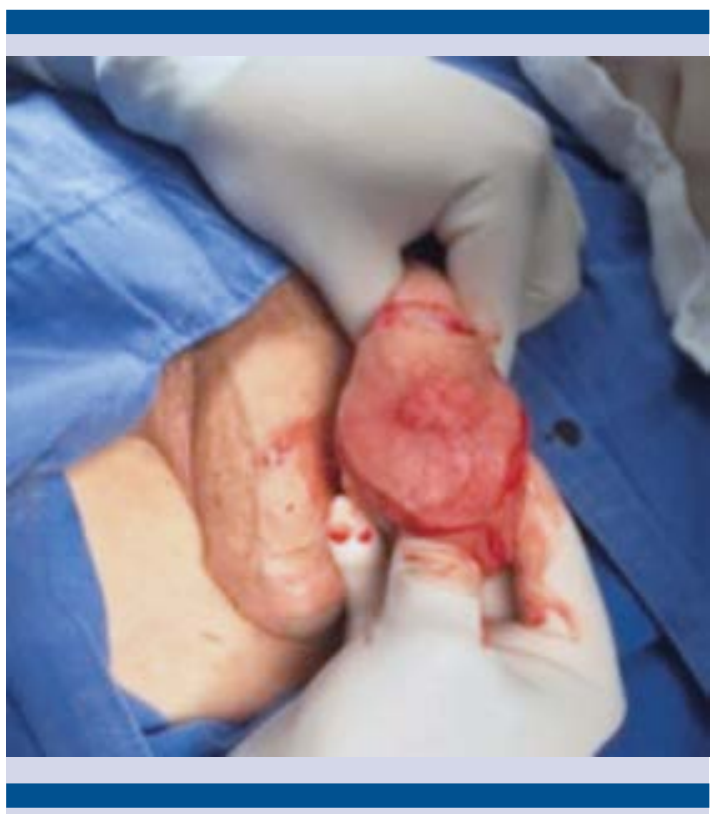

Figura 2. Tumorectomía con bordes amplios.

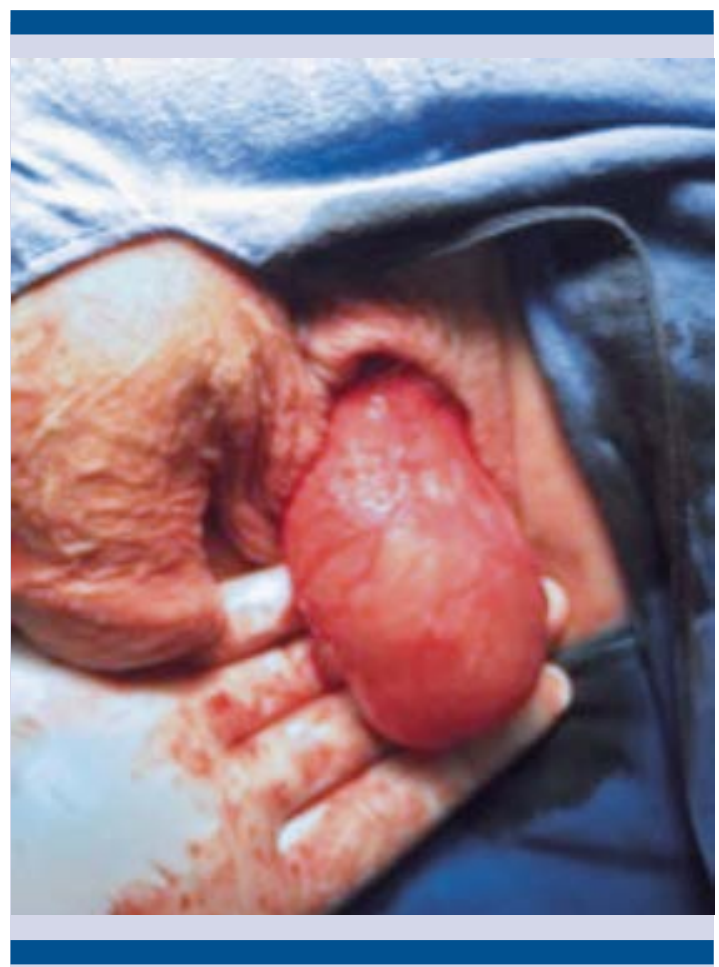

Figura 3. Testículo izquierdo sin afectación macroscópica. infiltración a la dermis, sin llegar al tejido adiposo.

- Microscópicos: neoplasia compuesta por células epiteliales escamosas malignas, que surgen de la epidermis e infiltran la dermis en forma de nidos, con queratinización individual y formación de perlas de queratina, citoplasma abundante eosinofílico y núcleos con atipia severa, relacionado con carcinoma escamoso invasor, bordes quirúrgicos libres de lesión, permeación a vasos sanguíneos venosos y linfáticos ausente (Figura 4).

El paciente tuvo evolución posquirúrgica adecuada; se descartó el tratamiento coadyuvante $y$ hasta el momento permanece en vigilancia.

\section{DISCUSIÓN}

El carcinoma de células escamosas del escroto es una neoplasia poco frecuente. Veerhoeven y su grupo describen una incidencia de 1.5 en 1,000,000 sujetos en países occidentales. ${ }^{5}$

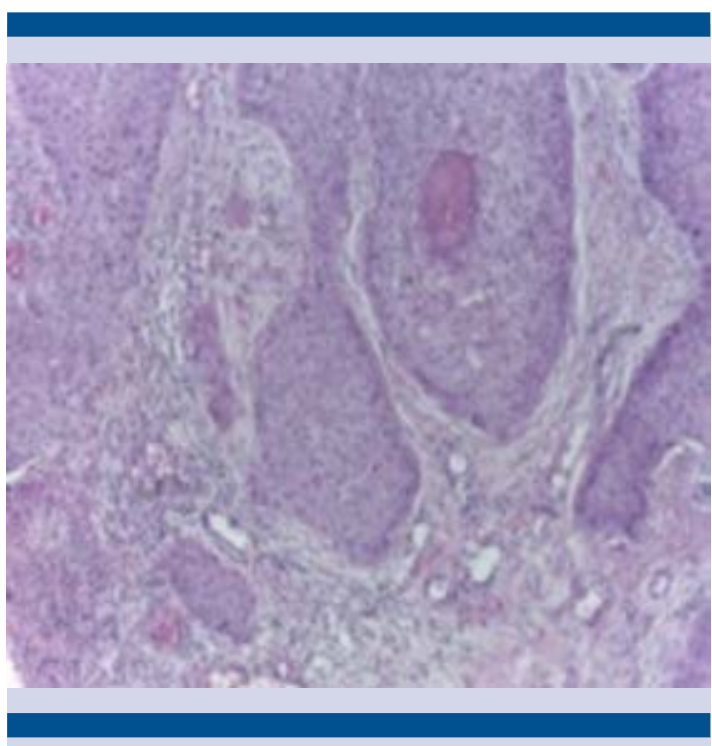

Figura 4. Neoplasia escamosa de origen escrotal (40x, H-E). 
En México no existen casos reportados de esta neoplasia.

El carcinoma de escroto tiene diferentes variantes histológicas, entre las más comunes se encuentran: carcinoma de células escamosas $(32 \%)$, enfermedad extramamaria de Paget (21\%), carcinoma de células basales $(18 \%)$ y sarcoma $(18 \%){ }^{12}$

El carcinoma de células escamosas del escroto se caracteriza por manifestaciones clínicas inespecíficas y su asociación ocupacional. La lesión se denominó "cáncer de Pott" o "cáncer de los deshollinadores" por la referencia histórica antes comentada; sin embargo, también afecta a los trabajadores del asfalto o mecánicos industriales. ${ }^{13} \mathrm{El}$ paciente de este estudio trabaja como fogonero, mecánico y permanece expuesto a múltiples químicos. De igual manera, el carcinoma de células escamosas del escroto se ha relacionado con procesos dermatológicos como: vitíligo, ${ }^{14}$ gangrena de Fournier previa, ${ }^{15}$ condilomas ${ }^{16}$ y, excepcionalmente, leishmaniasis, escabiasis, etc. ${ }^{17}$

El tratamiento de elección consiste en cirugía, con escisión completa, amplia y temprana del tumor. Dai y sus colaboradores informaron 10 pacientes con cáncer de escroto, tratados mediante resección amplia (sin tratamiento coadyuvante), con supervivencia global media de 118 meses. $^{18}$

La radioterapia y quimioterapia combinadas (metotrexato, bleomicina y cisplatino) durante cuatro ciclos está indicada para lograr una mayor supervivencia libre de enfermedad, incluso de 22 meses libres de recurrencia. ${ }^{18,19}$

El carcinoma de células escamosas del escroto es una neoplasia poco frecuente, que afecta a pacientes de edad avanzada. El cuadro clínico del paciente fue poco agresivo, con oportunidad de tratamiento temprano; se recomienda efectuar escisión amplia de la lesión, con bordes quirúrgicos negativos y vigilancia periódica. Algunos pacientes pueden requerir tratamiento coadyuvante.

El carcinoma de células escamosas del escroto es una neoplasia con características propias, pues se relaciona con la ocupación del paciente, además de la exposición crónica a diferentes agentes químicos o irritantes.

Los pocos casos reportados han sido aislados, por lo que no existe un consenso validado para el tratamiento de esta enfermedad.

\section{Agradecimientos}

A mis padres, hermanos y al resto de mi familia, por recordarme que la excelencia es una decisión diaria.

\section{Financiamiento}

Los autores no recibimos ningún tipo de financiamiento para la realización de este artículo

\section{Conflicto de intereses}

Los autores declaran que no tienen conflicto de intereses.

\section{REFERENCIAS}

1. Azike JE, Chukwujama NO, Oguike TC. Squamous cell carcinoma of the scrotum in a Nigerian: case report. Rare Tumors 2009;1(1):e2.

2. Peng W, Feng G, Lu H, et al. Case report of scrotal carcinoma and review of literature. Case Rep Oncol 2012;5:434-8.

3. Aparajita $M$, Agarwal $P$, Rajdeep $S$, et al. Squamous cell carcinoma of the scrotum - still an occupational hazard. Indian J Occup Environ Med 2014;18(3):150-152.

4. Rowland RG, Herman JR. Tumors and infectious diseases of the testis, epididymis, and scrotum. Adult and pediatric urology. Philadelphia: Lippincott, Williams and Wilkins; 2002. 
5. Verhoeven RH, Louwman WJ, Koldewijn EL et al. Scrotal cancer: incidence, survival and second primary tumours in the Netherlands since 1989. Br J Cancer 2010;26;103(9):1462-6.

6. Johnson TV, Hsiao W, Delman KA, et al. Scrotal cancer survival is influenced by histology: a SEER study. World J Urol 2013;31(3):585-90.

7. Wright JL, Morgan TM, Lin DW. Primary scrotal cancer: disease characteristics and increasing incidence. Urology 2008;72(5):1139-43.

8. Grundy D, Jones AC, Powley PH. Carcinoma of the scrotum associated with rubber urinals. Case report. Paraplegia 1993;31(9):616-7.

9. Lee LA, Fritz KA, Golitz L, et al. Second cutaneous malignancies in patients with mycosis fungoides treated with topical nitrogen mustard. J Am Acad Dermatol 1982;7(5):590-8.

10. Moy LS, Chalet M, Lowe NJ. Scrotal squamous cell carcinoma in a psoriatic patient treated with coal tar. J Am Acad Dermatol 1986;14(3):518-9.

11. Presti JC., Jr . Genital tumors. Smith's General Urology. In: Tanagho EA, McAnich JW, editors. New York: Mc Graw Hill, 2008;375-387.

12. Casasola J, Gutiérrez S, de Blas V. Scrotal carcinoma. Arch Esp Urol 2011;64(6):541-3.
13. Burmer GC, True LD, Krieger JN. Squamous cell carcinoma of scrotum associated whit human papilloma viruses. J Urol 1993;149:374-377.

14. Schwaab T, Nangia AK. Scrotal cancer. N Engl J Med 2005;19:2002.

15. Chintamani, Shankar M, Singhal V, et al. Squamous cell carcinoma developing in the scar of Fournier gangrene. Case report. BMC Cancer 2004;4:16.

16. Wright JL, Morgan TM, Lin DW. Primary scrotal cancer: disease characteristics and increasing incidence. Urology 2008;72(5):1139-43.

17. Friedman R, Hanson S, Goldberg LH. Squamous cell carcinoma arising in a Leishmania scar. Dermatol Surg 2003;29(11):1148-1149.

18. Dai B, Kong YY, Ye DW, et al. Basal cell carcinoma of the scrotum: clinicopathologic analysis of 10 cases. Dermatol Surg 2012;38(5):783-7.

19. Arai $Y$, Kinouchi T, Kuroda M, et al. A case of scrotal cancer with inguinal lymph node metastasis treated by multidisciplinary modalities including chemotherapy with methotrexate, bleomycin and cisplatin. Hinyokika Kiyo 1997;43(9):683-685.

\section{AVISO PARA LOS AUTORES}

Revista Mexicana de Urología tiene una nueva plataforma de gestión para envío de artículos: https://www.revisionporpares.com/index.php/RMUrol ahí podrá inscribirse a la base de datos administrada por el sistema Open Journal System (OJS) que ofrece las siguientes ventajas para los autores:

- Subir sus artículos directamente al sistema.

- Conocer, en cualquier momento, el estado de los artículos enviados, es decir, si ya fueron asignados a un revisor, aceptados con o sin cambios, o rechazados.

- Participar en el proceso editorial corrigiendo y modificando sus artículos hasta su aceptación final. 